\title{
Community Knowledge, Attitudes and Perception towards Mental Illness in Dodoma Municipality, Tanzania
}

\author{
Magreth Benedicto ${ }^{1}$, Erasmus Mndeme ${ }^{2}$, David.S.M. Mwakagile ${ }^{3}$, Tumbwene E. \\ Mwansisya $^{3}$ \\ ${ }^{1}$ St. John's University of Tanzania, School of Nursing, Dodoma, Tanzania \\ ${ }^{2}$ Mirembe Psychiatric Hospital, Dodoma, Tanzania \\ ${ }^{3}$ College of Health Sciences, The University of Dodoma, Dodoma, Tanzania
}

\begin{abstract}
Community attitude and perception towards mental illness play a major role in successful treatment and social reintegration of people with mental health problems. The aim of this study was to determine the knowledge, attitude and perception of the community towards mental illness in Dodoma Municipality. A multistage sampling technique was employed to select a sample size of 384 from the study population. A descriptive cross-section study was employed and semi-structured questionnaire were used in this study. The results showed that most of participants $85.9 \%(n=330)$ had poor knowledge about mental illness. Fifty one percent $(n=196)$ could not identify any type of illness, $58.9 \%(n=226)$ connoted negative attitude towards persons with mentally illness. Moreover $75.8 \%(n=291)$ of these had poor perceptions about mental illness. Poor knowledge, perception and negative attitude still prevail despite the fact that there is a National Mental Hospital located in Dodoma Municipality, Tanzania.
\end{abstract}

Keywords: Attitude, Community, Knowledge, Mental health, Mental illness, Perception.

\section{Accessible Summary}

- Mental and behaviour disorders are one of the challenges facing the world today. This study assessed knowledge, attitude and perception of the community towards mental illness in Dodoma Municipality. The study was completed in Tanzania.

- The community showed poor knowledge concerning mental illness, inability to identify types of illness and had negative perception about mental illness.

- The findings of this study show that, a good number of respondents had little knowledge about mental illness. The inability to identify the type of mental illness could be due to lack of health education on mental health and therefore lack of awareness for the appropriate treatment.

- This study provides the baseline findings for supporting health workers to empower the community members regarding knowledge of mental illness, in order to change the attitudes and perception of the community, as well as establishing health seeking behaviour for treatment of mentally illnesses.

\section{INTRODUCTION}

Mental illness (MI) is the term used to describe a broad range of mental and emotional conditions. It is also refer to mental impairments other than mental retardation, organic brain and learning disabilities (WHO, 2001). MI can be experienced over many years; the type, intensity and duration of symptoms vary from person to person. The most common forms of MI are anxiety disorders and depressive disorders.

Mental and behaviour disorders are so prevalent that more than $25 \%$ of people at a global level are estimated to experience this condition at some point in their life time. They affect each part of fabric of society including poor, rich, young or adult (World Health Report 2001).

The prevalence is on the increase each day as reported by the National of Mental Health in the United States of America (2003) indicated a probability of $20 \%$ of the population would be affected by some kind of mental illness at any one point of time of their lives and that a probability of $25 \%$ of people would have been familiar with someone with Mental illness. 
Studies have shown that people have limited knowledge and negative perception about mental illnesses in the community, and whenever there is any knowledge, it is based on prevailing local understanding of the nature and causation of MI (Asuni et al. 1994). People's beliefs regarding MI should not only be known, but the purpose of their beliefs should be understood; such attitudes and beliefs about MI can only be studied within a cultural context (Gureje et al.2006).

Community attitudes influence the help seeking behaviour of mental health sufferers. Ignorance about advances in the diagnosis and management of MI, the availability of effective treatment, and the fear of stigmatization may prevent people with mental disorders from seeking professional help (Hugo et al. 2003). Moreover, the community attitude and perception towards behaviour disorder or mental illness play a major role in successful treatments and social reintegration of the mentally ill persons. Also, these help in the determination of help seeking behaviour and adherence to drug treatment (Hugo et al. 2003).

Mental illness is a major problem in which two thirds of people who require treatment for MI have been reported that do not seek help because of stigma associated with the illness and its treatments (Stuart 2005). Since MI is a major problem globally and it is on the rise, therefore a study which explore the community's knowledge, attitudes and perceptions towards mental illness might useful to ameliorate this problem. There are numerous studies on knowledge and perception towards mental illness. However to best of our knowledge, to date, there is no any study explored the community knowledge, attitude and perception towards MI in Dodoma Municipality, Tanzania.

\section{Methods}

The research design was a descriptive cross-sectional study a quantitative method.

\subsection{Inclusion Criteria}

This study included people aged 18 years and above residing in Dodoma Municipality who were both males and females.

\subsection{Exclusion Criteria}

Those aged less than 18 years, refusal to participate, seriously ill persons, mentally sick and failure to speak Swahili or English were not included because consent was needed before administering the questionnaire.

\subsection{Sampling Technique}

A multistage cluster sampling was adopted for this study. In the first stage, by the use of the lottery method, one division among the four divisions of the Municipality of Dodoma was randomly selected. In the second stage, by using simple random sampling method, wards were selected from division that was selected in the first stage. In the third stage streets were chosen from the wards, which were obtained in the second stage. In the fourth stage, households were enumerated from each selected street and then were randomly chosen so as to get the required sample size. Any participant aged 18 years - old or above, from each household was considered a respondent for this study. In case of any refusal to participate, the replacement was made.

\subsection{Methods of Data Collection}

Data was collected from the respondents using a semi-structured questionnaire. The content of the questionnaire included socio-demographic variables, knowledge of the mental illness and its causes, attitude and perception of community members about mental illness. The sources of the questionnaire were from $\mathrm{Ng}$ and Chan (2000) a modified version of the questionnaire about mental illness in the Chinese Community; but modification was made to suit this study. A semi-structured questionnaire was adopted in this study in order to allow the respondents to give out their views concerning the questions asked. The questionnaire was designed in English language and then sent to the English department and then to the Kiswahili departments at St. John's University of Tanzania (SJUT) for translation into Swahili language. Finally it was again sent to the English department (SJUT) for final editing and to check for its validity.

\subsection{Validation of Research Instrument}

In order to test validity of the research instrument, pilot study was done before the actual study, where by 20 participants from two villages with characteristics similar to the study participants were interviewed. The participants included in the pilot study were not included in the actual study. In 
order to measure for reliability, Cronbach's alpha was calculated and the value of 0.791 was obtained from the data collected from the pilot study. Then, the researcher made the necessary corrections and modification of the instruments which were used in the actual study.

\subsection{Data Analysis}

The data were entered, cleaned and then analyzed by using the Statistical Package for Social Sciences (SPSS 17). Results are also presented using bar charts and graphs, which are used for the interpretations and discussions. Descriptive analysis was performed for proportions, percentages, means and their corresponding standard deviations.

\subsection{Scoring System}

Knowledge on mental illness was scored against questions which were asked. All responses were given equal weight. The mean score was calculated by taking total scores of knowledge on mental illness divided by the total number of all study participants; the correct answer was awarded one point and the wrong one zero point. Total knowledge score was 20 with a mean of 11.4, total score for attitude was 7 with a mean of 2.71 and total perception score was 3 with a mean of 1.21.

The mean score was used as a cutoff point to categorize the level of knowledge on mental illness. Respondents who got above the mean score were categorized as having a good knowledge while those who got less than the mean score were categorized as having poor knowledge towards mental illness.

\subsection{Ethical Issues and Confidentiality Consideration}

The ethical approval to conduct the study was obtained from the Research and Publications Committee of the University of Dodoma. Permission to conduct the research was obtained from the Municipal Director of the Dodoma Municipality. During the data collection, respondents were informed on the purpose of the study. Before questionnaire administration, consent form was given to each participant to sign and no name was required. In order to allow them to make an informed choice, informed consent included description of the aim and advantages of the study, the foreseeable and anticipated risks, care for psychological trauma that could result from the study and its duration were stipulated. The participants were free to withdraw from the study at any time when the feel so without any penalty.. Furthermore, to maintain privacy and confidentiality the answered questionnaires were kept and locked safely at a place where only the principle investigator can have access.

\section{RESUlTS}

\subsection{Social Demographic Characteristics}

Table1. Distribution of the study sample by socio-demographic characteristics $(N=384)$

\begin{tabular}{|l|l|l|}
\hline Particular & Category response & Frequency and percents $\mathrm{n}(\%)$ \\
\hline Gender & Male & $230(59.9)$ \\
\hline & Female & $154(40.1)$ \\
\hline Religion & Christian & $217(56.5)$ \\
\hline & Muslim & $162(42.2)$ \\
\hline & Others & $5(1.3)$ \\
\hline Age & $18-24$ & $88(22.9)$ \\
\hline & $25-34$ & $139(36.2)$ \\
\hline & $35-44$ & $103(26.8)$ \\
\hline & $45-54$ & $45(11.7)$ \\
\hline Marital status & $55+$ & $9(2.3)$ \\
\hline & Single & $163(42.4)$ \\
\hline & Married & $206(53.6)$ \\
\hline & Separated & $9(2.3)$ \\
\hline & Divorced & $4(1.0)$ \\
\hline Employment & Widowed & $2(0.5)$ \\
\hline & Peasants & $48(12.5)$ \\
\hline & Unemployed & $83(21.6)$ \\
\hline & Employed & $162(42.1)$ \\
\hline & Small scale business & $91(23.7)$ \\
\hline
\end{tabular}


Magreth Benedicto et al.

\begin{tabular}{|l|l|l|}
\hline Education & Informal & $12(3.1)$ \\
\hline & Primary & $112(29.2)$ \\
\hline & Secondary & $159(41.4)$ \\
\hline & College & $70(18.2)$ \\
\hline & University & $26(6.8)$ \\
\hline & Others & $5(1.3)$ \\
\hline
\end{tabular}

This study was done from December 2011 to June 2012. A total of 384 respondents were interviewed in which $\mathrm{n}=230(59.9 \%)$ were males. Mean age was 34.3 (SD 2.3) years. With regards to education category $n=159(41.4 \%)$ of respondents were secondary educated, $n=206(53.6 \%)$ were married, $n=$ $217(56.5 \%)$ were Christians and $n=162(42.1 \%)$ of the respondents were employed. The description on Table 1 above provides the detailed results of socio-demographic characteristics found in this study.

\subsection{Community Knowledge of Mental Illness}

Measurement of knowledge of mental illness focuses mainly on the general understanding of mental illnesses without necessarily focusing on the knowledge of specifics, knowledge of common signs that describes one to have a mental illness, knowledge of types, knowledge of causes and knowledge of treatment options for mental illnesses.

Aiming at obtaining the respondents' broad knowledge about mental illness, the variables were assessed by asking the responded on how much they knew about mental illness. More than half of the respondents $n=225(58.6 \%)$ reported little knowledge of MI, as opposed to less than one tenth $n=32$ $(8.3 \%)$ who claimed a good knowledge about MI. The description on Table 2 below provides the detailed results of knowledge that was found in this study.

Table2. Community knowledge on mental illness $(N=384)$

\begin{tabular}{|l|l|l|l|}
\hline & Frequency & & Percent \\
\hline Responses & $(\mathrm{n})$ & & $(\%)$ \\
\hline A good deal & 32 & & 8.3 \\
\hline A little & 225 & & 58.6 \\
\hline Very little & 95 & & 24.7 \\
\hline Don't know & 32 & & 8.3 \\
\hline
\end{tabular}

\subsection{Community Knowledge on Sign and Symptoms of Mental Illness}

Ninety four percent $(94.3 \%, \mathrm{n}=362)$ of the respondents reported to have had ever seen a MIP and $\mathrm{n}=$ $22(5.7 \%)$ had never seen one. Common symptoms of MI reported by respondents were abnormal behaviors $n=183(50.3 \%)$, and talking alone $n=50(13.7 \%)$ as indicated by Figure 1 below.

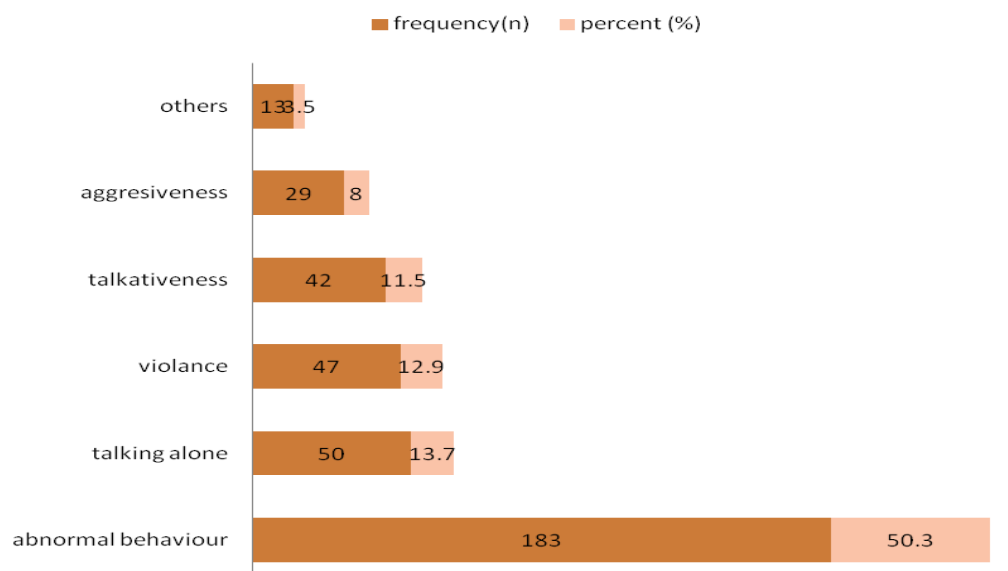

Figure1. Distribution of study population by knowledge on signs and symptoms of mental illness $(N=364)$

\subsection{Community Knowledge on Types of Mental Illness}

Results shows that, a total of respondent $n=196$ (51.0\%) did not know the types of MI while drug induced psychosis was reported by many respondents; $n=66(17.2 \%)$. Further description of what respondents reported about the types of mental illness are found in Figure 2 below. 


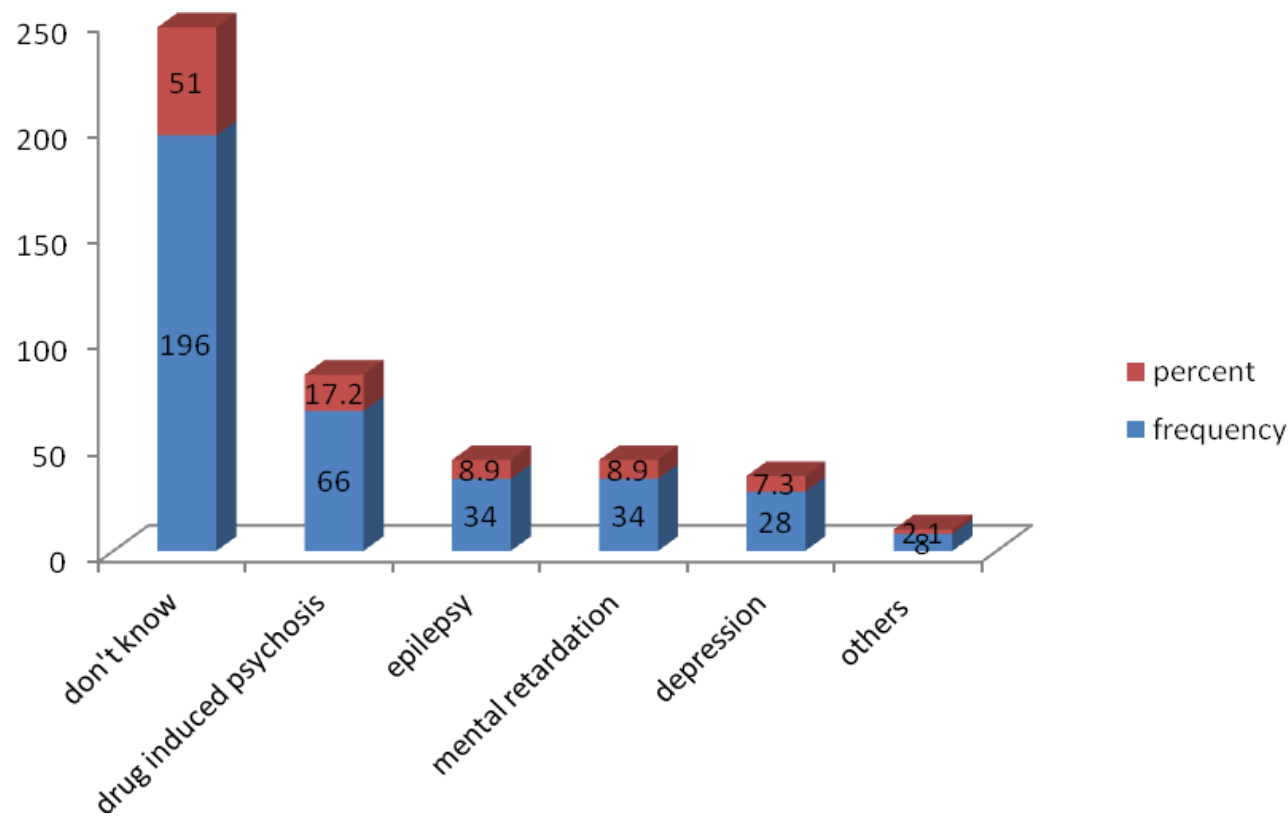

Figure2. Distribution of study population by knowledge on types of mental illness $(N=384)$

\subsection{Community Knowledge of Causes of Mental Illness}

Substance abuse (alcohol and/or drugs, but mainly the latter) was identified by majority of respondents $(n=289(75.3 \%))$ as a causes of MI, while very few $n=40(10.4 \%)$ agreed that curses could be causes of mental illness. Many other causes were identified by respondents to be the causes of mental illness as is shown in Figure 3 below.

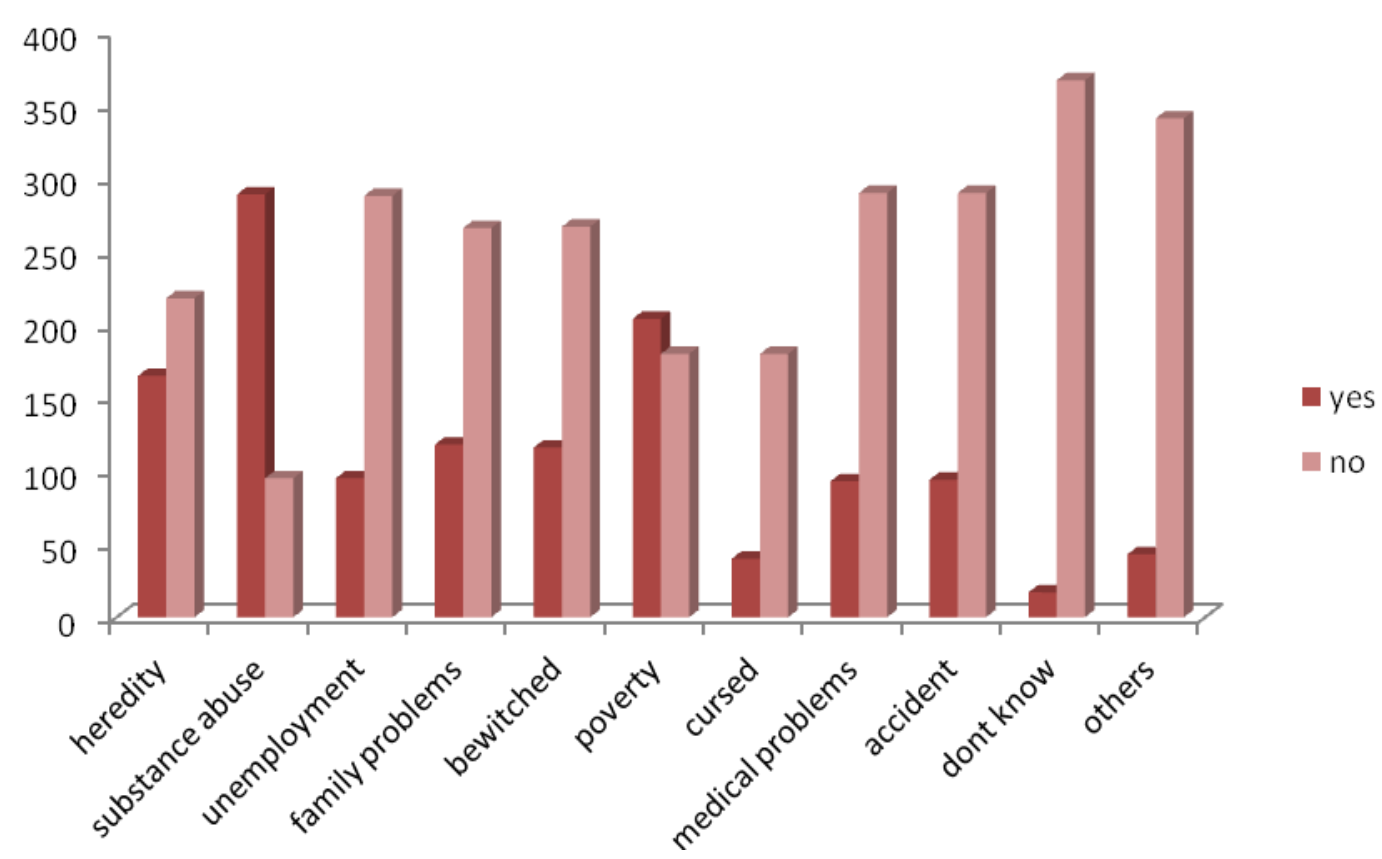

Figure3. Distribution of study population by knowledge on causes of mental illness ( $N=384$ )

\subsection{Community Knowledge about Treatment of Mental Illness}

One among other, in the measurement of knowledge of mental illness, was knowledge of treatment options. Total number $n=330(86.2 \%)$ of respondents, identified mental hospital/institution to be the treatment option for mental illnesses and while other group of respondents $n=148(38.5 \%)$ identified counselling to be their option for treatment of mental illnesses as summarized in Figure 4 below. 


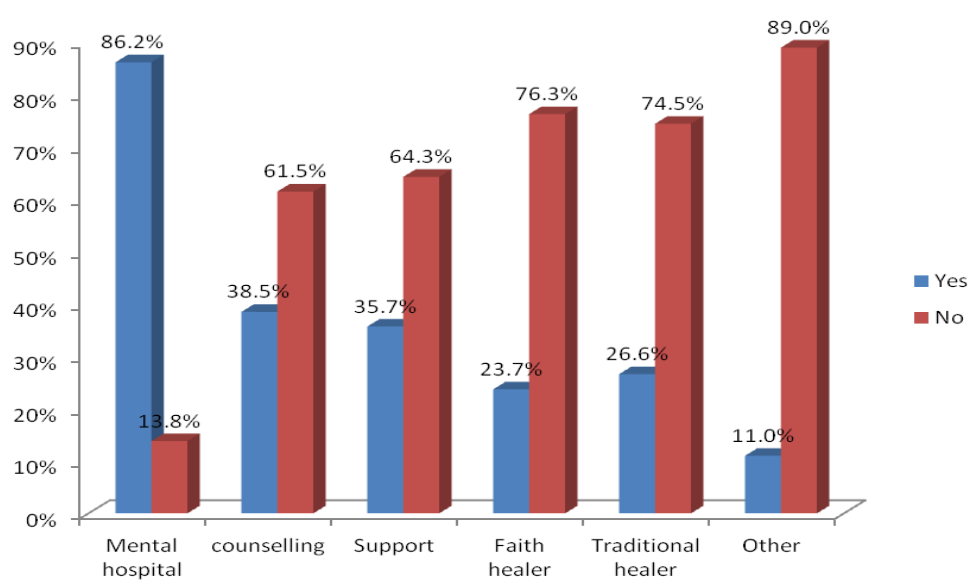

Figure4. Participants' knowledge on treatment measures of mental illness $(N=384)$

When respondents were asked if a mentally sick person could live a healthy life in the community, $\mathrm{n}=$ $205(53.4 \%)$ said no. Stigma was cited as the reason for not living a health life by $\mathrm{n}=120(60.9 \%)$ while $n=254(66.1 \%)$ reported that they cannot make friendship with a MIP. Other findings are indicated in Table 3 below.

Table3. Attitudes and perceptions toward mental illness among the participants in the study sample $(N=384)$

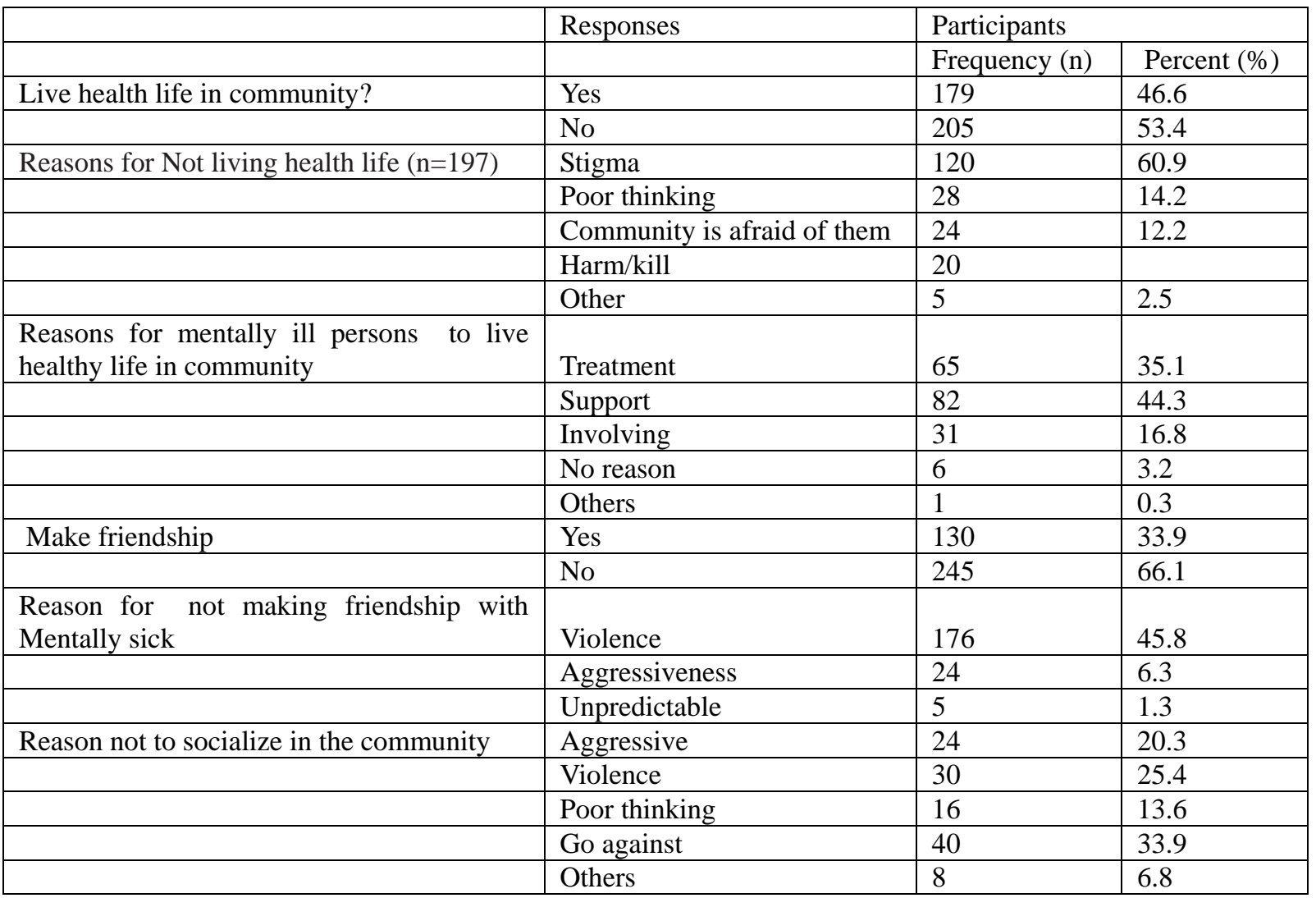

A total of $n=193(50.5 \%)$, of the participants reported that a MIP cannot do a regular job when asked if a mentally ill person could do a regular job (figure 5); while $n=69(35.6 \%)$ reported that they cannot have a regular job because they will be making mistakes and ruin the job (Table 4).

Table4. Participants' perception on reasons for Mental Ill People not to do regular job $(N=194)$

\begin{tabular}{|l|c|c|c|}
\hline & & frequency & \multicolumn{1}{c|}{ percent } \\
\hline Responses & & $(\mathrm{n})$ & \multicolumn{1}{c|}{$(\%)$} \\
\hline make mistakes & & 69 & 35.6 \\
\hline poor concentration & & 58 & 29.9 \\
\hline causes damage & & 49 & 25.3 \\
\hline need treatment first & 17 & 8.8 \\
\hline other & & 1 & 0.5 \\
\hline
\end{tabular}


Eighty six percent, $\mathrm{n}=332(86.5 \%)$ of the study population reported that they will feel good if a mental health facility was set up in their community and the reasons are summarized in Table 5 below.

Table5. Participants' attitude towards mental health facility set up in the community $(N=379)$

\begin{tabular}{|l|l|r|}
\hline Responses & Frequency $(\mathrm{n})$ & Percent (\%) \\
\hline Save the patients & 184 & 48.5 \\
\hline Reduce the number of patients & 62 & 16.4 \\
\hline Center of education & 49 & 12.9 \\
\hline Increase manpower & 27 & 7.1 \\
\hline Bring noise & 26 & 6.9 \\
\hline May harm people & 12 & 3.2 \\
\hline Increase interaction & 10 & 2.6 \\
\hline Move away & 9 & 2.4 \\
\hline
\end{tabular}

\section{DISCUSSION}

To best of the researcher's knowledge, this is the first study to explore the community knowledge, attitudes and perception towards mental illness in Dodoma municipality. The outcomes of this study suggested that knowledge about mental illness was poor in Dodoma community.

In the present study, the majority of the respondents $(41.1 \%)$ had secondary school education which implies that one would expect that they could have sufficient knowledge and good perceptions about MI, and therefore have positive attitudes towards people with mental health problems. However, on the contrary, their knowledge of MI was found to be poor. The reason behind could be due to the absence of mental health education program to the community members.

The findings of this study showed that a good number of respondent, 58.6\% had little knowledge about MI. These further indicated that they could react strangely to someone who is mentally ill. In addition, $50.3 \%$ of the respondent claimed that they would recognize a person with mental health problems by his or her abnormal behaviour. This kind of perception would induce the community to brand anyone with abnormal behaviour as being mentally ill even when this person might be merely acting out. Moreover this implies that the community would not be able to recognize a person in remission or less severe phases of MI. This finding is in agreement with what was found in a study done in Ethiopia by Deribew \& Tamirat (2005) which reported $60 \%$ of the respondents reported abnormal behaviour as the sign of MI.

Despite the fact that a great number of the respondents (94.3\%) in this study reported to have seen a person with mental health problems, they could not identify the type of MI the person was suffering from. This could be due to the fact that in Dodoma, one is likely to see a MIP because a mental hospital is located in this community. The inability to identify the type of MI could be due to lack of health education on mental health and therefore lack of awareness of the types of MI. The unawareness can curb the capability to help a MIP seek proper treatment and in turn lead to misperception about MI and negative attitude towards people with mental health problems.

The identification of substance abuse, drugs in particular, by most of the participants $(75.3 \%)$ in this study as a major cause of MI can make members of the community to be prone to sweeping generalizations or stereotyping that all people with mental health problems are drug and/or alcohol addicts. This finding concurs with what was found in a study done in Nigeria by Gureje et al. (2005) in which substance abuse was stated to be the major cause of MI by $80.8 \%$ of respondents.

The finding in this study show that there was almost an equal split between those $(53.1 \%)$ who asserted that poverty was the cause of MI and those (46.9\%) who disagreed. These results are in agreement with the findings of the study conducted by Deribew and Tamirat (2005) which found out that $55 \%$ of the respondents chose poverty. Furthermore, the observations indicate that the study population did not attribute heredity and family problem as being possible cause of MI. This implies that the study population was unaware of other possible causes of MI.

This also underscores the belief of the Dodoma community that substance abuse is the prime cause of MI. This ignorance could result into negative perceptions about the condition.

The finding in this study shows that the majority of the respondents $(86.2 \%)$ mentioned the best model of treatment as the hospital concurs with what was found in a study by Kabir et al. (2004) in North Nigeria. However, this finding is in disagreement with what was found in a study by Gureje et 
al. (2005) in Nigeria in which traditional healing was the most preferred treatment. The preference of hospital treatment of MI noted in this study $(86.2 \%)$ could be attributed to a number of reasons such as higher education of the study population, the presence of a mental hospital in Dodoma and religiousness of the studied community.

In this study, negative attitudes towards people with mental health problems were very prevalent among the study population (58.9\%) indicated by responses such as MIP cannot live a better life and that they cannot make friendship with them. This is in agreement with what was found in study done on health workers in Delta State in Nigeria by Kamla (2009). Factors which facilitated this negative attitude towards MI included stigma, violence behaviour of MIP, impaired cognitive functioning and lack of knowledge towards MI among community members. The findings in this study are also supported by the study done in Kinondoni Tanzania by Chikomo (2011).

Also the responses such as MI cannot perform a regular jobs, are aggressive and dangerous indicate that perceptions of the study population towards people with mental health problems generally poor. These perceptions are true only for patients in the acute phase of MI but not when the patients are in remission or after getting effective treatment. Although majority of respondents said would feel good if a mental health facility is set up in the street, some of the explanations would reduce the number of patients in the street implies that they have a negative attitude and poor perception toward mental illness.

\section{CONClusion}

Poor knowledge, perception and negative attitude still prevail in Dodoma Municipality despite the fact that there is a National Mental Hospital located here.

This was due to lack of community mental health education programs. Therefore there is a need for community mental health education in order to improve the knowledge, attitudes and perception of the public towards MI. This may encourage early health seeking behavior, as well as better treatment outcomes.

This research provided a baseline to health workers to empower the community members regarding knowledge of MI, in order to change the attitudes and perception of the community, as well as the health seeking behaviour of people with mental health problems.

Also to inform the mental health policy developers/makers of the mental health curriculum, to develop programs which will help mental health care providers to assist the community, provide care and facilitate mental health education effectively. And finally to stimulate further research regarding mental health knowledge, attitudes and perception, in order to improve knowledge and a change in the attitudes and perception of the community, as well as the health seeking behaviour of people with mental health problems.

\section{RECOMMENDATION}

The Ministry of Health and Social Welfare should sensitize the community, through campaigns and workshops in churches, schools, Non Governmental Organisations and all sectors raise community awareness and to modify the negative attitudes and perception of the community towards people suffering from MI.

There should be educational programs conducted by mental health care providers for rehabilitation of people with mental health problems and their families in the community.

More qualitative research should be done to explore more on the factors which contribute to negative attitudes and poor perception of people living with mental illness.

\section{REFERENCES}

Asuni T., Schoenberg F. \& Swift C. (1994), editors: Mental Health and Disease in Africa. 2nd edn. pp 42-53. Spectrum Books Ltd, Ibadan.

Bourget B. \& Chenier R. (2007) Mental Health Literacy in Canada: Phase One Report on Mental Health Literacy Project. Canadian Alliance on Mental Illness and Mental Health, Canada. www.camimh.ca/files/literacy/MHL_REPORT_Phase_One.pdf 
Chikomo J.G. (2011) Knowledge and Attitude of the Kinondoni Community Towards Mental Illness.Dissertation presented to the university of Stellenbosch in South Africa. URL: http://hdl. handle.net/10019.1/6562

Cochran W.G. (1997) Sampling Technique ( $3^{\text {rd }}$ Ed.) New York: John Wiley \& sons

Deribew A. \& Tamirat Y. S. (2005) How are mental health problems perceived by a community in Agaro town? Ethiopia Journal of Health Development 19(2), 153-159.

Gureje O., Lasebikan V. O., Ephraim-Oluwanuga O., Olley B. O. \& Kola L. (2005) Community Study of Knowledge of and Attitude to Mental Illness in Nigeria. British Journal of Psychiatry 186, 436-441. http://bjp.rcpsych.org/content/186/5/436.long

Gureje O., Olley B. O., Ephraim-Oluwanuga O. \& Kola L. (2006) Do Beliefs About Causation Influence Attitudes to Mental Illness? World Psychiatry 5(2), 104-107. http://www. ncbi.nlm. nih.gov/pmc/articles/PMC1525129/

Hugo C. J., Boshoff D. E. L., Traut N. Z. \& Stein D. J. (2003) Community Attitudes Towards and Knowledge of Mental Illness in South Africa. Social Psychiatry and Psychiatric Epidemiology 38(12):715-9. http://link.springer.com/article/10.1007\%2Fs00127-003-0695-3

Jorm A. F., Angermeyer M. C. \& Katschnig H. (2000) Public Knowledge of and Attitudes to Mental Disorders: A Limiting Factor in the Optimal Use of Treatment Services. In Andrews, G. \& Henderson, S. (Eds.). Unmet Need in Psychiatry: Problems, Resources, Responses. 399-413. Cambridge: Cambridge University Press.

Kabir M., Iliyasu Z., Abubakar I. S. \& Aliyu M. H. (2004) Perception and Beliefs about Mental Illness among Adults in Karfi Village, Northern Nigeria. BMC International Health and Human Rights 4, 3. doi: 10.1186/1472-698x-4-3.

Kamla R. (2009) Knowledge, Beliefs and Attitudes of Health Care Providers towards the Mentally Ill in Delta State, Nigeria. Annals of General Psychiatry 8,19. doi: 10.1186/1744-859X-8-19.

Razal G. \& Hajib H. (2000) Community Attitudes towards the Causes of Auditory Hallucination in Saudi Arabia and Canada. Acta Psychiatric Scandinavia 114, 303-318.

The World Health Report (2001) Mental health: New understanding; New Hope. WHO, Geneva

WHO (1994) Mental Health Care in Developing Countries; A Critical Appraisal in Research Findings. Technical Report Series, 698, WHO, Geneva, Switzerland. 